\section{THE CANCER PROBLEM.}

A Summary of the Lloyd Roberts Memorial Lecture.* BY

W. E. GYE, M.D.,

PATHOLOGIST, MEDICAL RESEARCH COUNCIL'S FARM LABORATORIES, MILL IILL.

I DEsIRE to express my thanks for the honour of being asked to deliver this, the fourth of the lectures established to perpetuate the memory of Lloyd Roberts. The subject which I have chosen for the lecture is not entirely within the special field of medicine in which Lloyd Roberts was an acknowledged master, but my hope is that what $I$ have to say will be of sufficient interest to make the lecture worthy of the occasion,

I shall begin by indicating at once my general viewpoint on the subject of cancer, and I cannot do better than quote a few words from the introductory note of the first scientific' report of the Imperial Cancer Research Fund (1904) :

"The combined histological and clinical observations of the last fifty years have established the malignant new growths as a natural group related to each other by fundamental common attributes. The explanation of those common fundamental characters is bound up with the mode of origin of malignant new growths, and is the problem awaiting solution, to be followed by the specific explanation of individual variations as its natural corollary."

I do not know how far this would meet with general approval. There are some very distinguished pathologists who take the view that there is no common cause of the fundamental characters of now growths; to such the search for a cause of the disease is an irrational pursuit. This view I regard as simply obscurantist, and so, perforce, I leave it to time and the progress of knowledge to decide the issue.

My task is to tell briefly the essential story of the attempts which have been made to solve the problem set out in the quotation above. Naturally I shall advocate my own views of the solution of the problem, but I am more anxious to show-and if $I$ fail the fault lies with me and not with the facts-that at least the problem has been defined and brought to a practical stage by the immense efforts of experimental pathologists during the last twenty-five years.

The earliest record of cancer experiments goes back to 1775, when Peyrilhe attempted to transfer a human breast cancer to a dog. The experiment was a failure. It has been repeated, with variations, over and over again by numerous observers-by Dupuytren, by Langenbeck (1840), Lebert and Follin, Duplay and Cazin, etc.-and invariably without success. Roux and Metchnikoff, and also Jobling, have attempted to transfer human tumours to anthropoid apes, and failed. All this early work has shown the impossibility of transferring human tumours to the lower animals.

In 1889 Hanau described the first successful transplantation of a carcinoma within the same species. The tumour was of a rat, and in structure was a squamous-cell carcinoma. It was transplanted into two other rats and formed small nodules in 'both. Pfeiffer (1890) was successful in transferring a melanotic carcinoma of a mouse to other mice. Von Eiselsberg (1890) successfully transplanted a spindle-cell sarcoma of a rat to another rat. Morau (1891) was the first, by the method of transplantation, to cultivate a tumour. He was able to maintain a carcinoma of a mouse for seventeen generations over a period of three years by the inoculation of fragments of the tumour into other mice Firket (1882) and Velich (1898) were successful in transplanting a spindle-cell safcoma and a subperiosteal sarcoma of the rat respectively.

These observations attracted but little attention, and it was not until Jensen, Loeb, and Borrel had turned their attention to them that the significance of such work began to be appreciated. The present era of experimental cancer research may be said to date from the publication of Jensen's paper in 1902. His work, which was carried out with a carcinoma of a mouse, confirmed the observations of the previous experimenters already mentioned, in showing

* Delivered at the Royal Infirmary, Manchester, November 9th, 1926. that a malignant tumour can be transmitted indefinitely within the species in which the tumour arises. Further, Jensen was unable to find micro-organisms in the transplanted tumours, and described experiments in which was tested the resistance of the cancer cell to different agents. During the same period: Loeb studied a cystic sarcoma of the thyroid of the rat and obtained results essentially similar to those obtained by Jensen. Borrel, working with a mouse carcinoma, added further confirmation.

It will have been observed that the animals used by the experimenters mentioned were rats and mice, and the question now arose as to the occurrence of true new growths in other species, In the first scientific report. of the Imperial Cancer, Research Fund a list is given of the animal tumours examined in the laboratories of the Fund during the year 1903. Tumours of the most varied histological kinds, sarcomata and carcinomata, of the following animals are mentioned: cow, dog, horse, sheep, pig, mouse, cat, hen, Indian parakeet, giant salamander, cod, gurnard, and trout. Since that time observations of pathologists throughout the world have established definitely the fact that new growths occur commonly in all the lower animals, both domesticated and wild. Cancer is not, therefore, a purely human disease, and any explanation of cancer in man must also explain the phenomena presented by cancer in the lower animals. These observations are uncontested and are of fundamental importance; they rule out of account the all too frequent pronouncements that cancer is a disease of civilization and can be abolished by a return to a " natural " mode of living-whatever that may mean.

In the literature of twenty years ago may be found papers in which doubt was thrown on the neoplastic nature of animal tumours, but the question has now been most thoroughly studied, and the opinion among those most competent to judge is that the animal tumours are true new growths. It is therefore no longer necessary to discuss the point at any length. It is sufficient to say that in mode of origin, in age incidence, in clinical course, in mode of growth and infiltrative spread, and in the formation of metastases, there are no differences between tumours of man and of animals. The same range of tumours, benign and malignant, is met with in animals, and it is with this material that the greater part of experimental studies have been carried on.

The method by which a tumour is transferred from one animal to another consists in the implantation, usually subcutaneously, of a fragment of the tumour by means of a trocar or a syringe. From the implanted fragment a new tumour arises. Is the new tumour produced by infecting the cells of the host, or does it arise by multiplication of the cells implanted? This question was studied by Jensen by the following technique. A series of animals - mice-was inoculated, in the manner indicated, with a mouse carcinoma, and at regular intervals one of the inoculated mice was killed, the whole of the graft and surrounding tissues fixed and cut in serial sections. In this way the fate of the implanted cells could be followed. Jensen showed decisively for a carcinoma-and his results have been confirmed by numerous observers-that the daughter tumour is derived entirely from the cells of the implanted graft. The central portion of the graft dies, but the peripheral cells live; the fate of the implanted stroma of the graft is difficult to follow, but a new stroma is provided by the host, and it is this which nourishes the rim of neoplastic cells of the implanted fragment. The process, then, is a true transplantation and not an infection. Loeb, who studied the same problem with a rat sarcoma, was unable to come to a decided opinion. He inclined to the belief that the new tumour was derived partly from the malignant cells inoculated and partly, by a process of infection, from the connective tissues of the ast. This difference in finding, however, may be merely one of technique and depending upon the difficulty of recognizing a malignant from a normal connective tissue cell. Wherever the cells of the implanted tumour are easily distinguished from the cells of the area in which the fragnent is placed, the question at issue may be determined by early-stage examinations. The general result of an immense amount of investigation of this character has been to show that the inoculations of tumours are true 
transplantations, that the daughter tumours are derived from the cells of the original new growths, and that the inoculated animals merely act as a medium in which the cells proliferate. By losing sight of these fundamental facts and by regarding transplanted tumours as new growths cancer research has often been led into blind alleys.

The failure of the earliest investigators of cancer to transfer the human disease to lower animals has been mentioned already. This failure probably played a large part in forming the opinion that cancer is essentially a human disease. But it was quickly shown by experimental research that the tumours of animals are transplantable only within the species in which they occur. Thus a dog tumour cannot be propagated in a cat, or a cat tumour in a dog. In the light of the discoreries of experimental histologists this is easily understood. It has been shown that inoculations of tumours are transplantations, and therefore it could not be expected that the cells of a dog, for example, would grow indefinitely in cats or any other species of animal than the dog. The cell of an animal carries the species specificity. Certain observations have been made which would appear to invalidate this conclusion. Murphy discovered that mammalian tumours can be grown in a developing chick embryo. This discovery has been confirmed by many observers, including myself. From a minute fragment of a mouse carcinoma a considerable amount of growth can be procured, and the astonishing picture is obtained of mouse epithelial tissue growing rapidly around a stroma provided by the chick embryo, new blood vessels in which course nucleated red cells penetrating the mass of growth.

The same phenomenon of heteroplastic growth can be obtained in mammals by inoculating a mouse sarcoma into new-born rats. The cells proliferate and form a large tumour, which can again be transplanted into new-born rats. In this way it is possible to maintain a mouse sarcoma for several generations in rats. But such work has no real bearing on the cancer problem. The implanted cells remain mouse cells, and the maintenance of the tumour for a few weeks or months in a series of new-born rats is merely a laboratory trick which leaves the main problem unaffected.

Since daughter tumours are derived from the implanted tumour cells it follows that living cells must be inoculated in order to obtain a second tumour. With epithelial tissues this is obvious indeed; inoculations are usually made subcutaneously into the connective tissues, and the formation of an epithelial daughter tumour could not be expected to occur from infection of connective tissue cells. It is, however, an experimental fact that when the cells of a tumour are killed, whether by heat or by dyying, by means of antiseptics or by mechanical disintegration, the mass of dead material no longer possesses the power of giving rise to a tumour when it is inoculated into a suitable animal. Thus, coincident with the death of the tumour cell, there disappears the power of inducing a daughter tumour. The fact fits exactly with the logical deductions from the histological analysis of the changes accompanying the processes of transplantation.

Such beautiful interlocking of fact and deduction served to strengthen the already strong conviction that the tumour cell is itself, as it were, the parasite. Nothing, apparently, is separable from the malignant cell which can induce the formation of a new tumour, and the general opinion has been reached, and is now held almost as a dogma, that the malignant cell is one which, under the influence of many possiblo inciting causes, has assumed a character or quality which enables it to grow and divide steadily and persistently beyond the needs of the rest of the body. According to this vicw the cell itsclf is a parasite. Tho position is most clearly indicated by the following facts. It is now possible by following the brilliant work of Yamagiwa and Ishikawa to induce tumours in rats and mice by repeated applications of tar to the skin or subcutaneous tissues. The tumours thus produced are typical new growths and behave in every respect like spontaneous tumour's which are caused in some way which we do not jet understand. A tar tumour of a mouse-carcinoma or sarcoma-can be transferred by transplantation to other mice, but living cells aro necessary for success. It cannot be successfully transplanted to a rat or to any other species of animal. It is as much an individual mouse tissue as a mouse is an individual mouse. In the same way a rat tar-tumour can be transplanted successfully only to other rats, and only by the inoculation of living cells. We thus arrive at the interesting position that one and the same irritant acting upon two siecies of animals will induce new growths in each species, but the new growth in each case is individual and particular to its own species. Clearly the extrinsic agent, the tar, has incluced an intrinsic change in the cell. It is thus easy to understand why a microbic hypothesis of the origin of tumours is met with scepticism and indeed contempt. It would be strange were it otherwise. Nevertheless, I believe that these apparently conclusive facts merely conceal the truth.

And now I come to the exceptions in all this mass of tumours. I refer to the well known fowl tumours described by Peyton Rous. For the purpose of simplification I shall describe and discuss only one of these tumours, the first to be discovered, and the one which is in the hands of pathologists all over the world. It is a spindle-cell sa"coma, of primitive type, which occurred spontaneously in a Plymouth Rock variety of the domestic fowl. The tunour was first described in 1910, when it was shown to be transplantable in the usual way, but to exhibit an unusual degree of specificity for the variety of bird in which it originated. Indeed, the early transplantations were successful only in blood relations of the fowl which bore tho spontaneous tumour. Now, after many years of artificial transplantation, the tumour grows in almost any variety of fowl, but, like mammalian tumours, it retains its species specificity strictly-that is to. say, it will not grow in pigeons, ducks, or any other species of bird, or in any mammal. Now this tumour was found by Peyton Rous to differ from all other tumours examined up to that time in being transferable to fowls, not only by means of living cells but also by means of dried tumour tissue or by means of cell-free filtrates. The cell-free filtrates, therefore, con. tain the tumour's " cause." And, most surprising fact of all, the filtrate is infective only for fowls, and causes the reproduction invariably of exactly the same kind of tunour-a spindle-cell sarcoma. Thus the agent derived from the tumour cells has the power of exciting the formation again of a new tumour by transforming the normal connective tissue cell of the fowl into malignant cells, and this power is exerted only in one species. It is easy to believe in the specificity of animal cells, but here apparently the specificity is freed from the cells and is obtained in solution-or at least it passes through a filter.

Of such tumours half a dozen or so have been described : but it does not matter much whether the number be half a dozen or half a hundred: the problem to be faced is the same and is challenging to all of us. Before trying to make clear what I conceive to be the problem, I will stato and discuss briefiy the essential facts upon which there is general agreement.

First, the tumour is a true new growth as judged by the most rigid standards; secondly, filtrates through candles which hold back very small bacteria are able to induce sarcoma formation; and thirdly, some of the properties of the filterable agent are those which wo usually associate with living organisms.

The general reaction to the discovery of these tumours was ono of surprise that such a tumour should exist, followed by a half-hearted denial of the neoplastic nature of the growth. To-dxy most pathologists who z-is a-udied the tumour agree as to its neoplastic nature. There exists, however, an unwillingness to consider seriously the possibility of the filterable agent being an ultra-microscopio microbe such as we believe exists in certain animal diseases. Some of the more absurd explanations of the peculiarity of this tumour I will simply mention. It has been suggested that the filtrate of the tumour contains an ultra-microscopio cell which, when injected into the muscle of a fowl, enlarges and becomes a normal cell from which the new tumour forms. A modification of this view which has been put forward is that the active filtrate contains a part of the cell from which the normal cell can again regenerate. Such views, I hope, need no reply. They are stated merely. 
to indicate the extremes to which men will go to explain away a fact which runs counter to a strongly held opinion.

Rous and his collaborators in their long researches into the filterable tumours came to the opinion that the balance of evidence was in favour of the agent being a living, filterable micro-organism. Now what is the evidence that such things exist at all? If we take the classical example, and the first discovered, of an animal disease believed to be caused by a filterable virus we shall consider foot-andmouth disease.

The current belief that foot-and-mouth disease is caused by a filterable virus is founded upon the following evidence. When the vesicular fluid of a lesion in this disease is diluted and filtered through a good candle, and the filtrate is injected into a normal animal, this animal aequires the typical signs and symptoms of the disease. The vesicular fluid obtained from the second case may again be diluted and filtered, and once again the filtrate will reproduce foot-and-mouth disease ; and so on ad infinitum. The filtrate when examined by ordinary microscopic and cultural methods is sterile, but since the causal agent reproduces itself indefinitely in the bodies of the inoculated animals it must be a living thing, and it is, as we have seen, of ultra-microscopic size. Upon this evidence almost all bacteriologists believe that the cause of foot-and-mouth disease is an ultra-microscopic microbe. The evidence produced by Peyton Rous with regard to the filterable tumours was of the same kind and quality, and is now more extensive. But opinion against a microbic cause of tumours is strong, and few are prepared to accept for tumours conclusions which, on similar evidence, are unquestioned in other fields of medicine.

Let me now state the problem which is before all of us. Thousands of tumours of men and animals have been studied. Large numbers have been cultivated by transplantations. A considerable number of tumours have been induced de novo by means of chemical and other irritants, and have been carefully studied. Almost all attempts to find an extrinsic cause-or a cause separable from the cells -have failed. But for about half a dozen tumours, of various histological kinds, a cause, a filterable virus, separable from cells, has been found. How shall we look upon this astonishing difference? We may regard the filterable tumours as a disease sui generis unrelated to other tumours; in this way we must suppose that a filterable virus plays a part in the causation of certain tumours which is comparable to the part played by tar or soot in others. This attitude to the problem has been general, but I think that it is a mere evasion of a very real difficulty. The problem exposed by the work of Rous does not consist solely in the isolation and cultivation of a virus. The true explanation of these tumours must, in the first place, decide whether or not a virus is present; and in the second place, equally important from the point of view of the cancer problem, must give us some understanding of the extraordinary specific character of active filtrates.

For my part I agree most emphatically with Rous, Murphy, and Tytler that " the findings with the chicken tumours largely demolish the theoretical basis on which objections to an extrinsic cause for cancer have been built up." But can these positive findings of Rous be reconciled with the negative results of similar experiments made with the majority of other tumours? I think they can.

\section{The Filterability of the Rous Tumour.}

It has already been pointed out that the exceptional character of the tumour lies in the fact that cell-free extracts are able to cause the formation of a new tumour. This property of the tumour must therefore be carefully studied, and we must know how far it is a fixed and constant property. It has generally been looked upon as constant, and the tumour has on this account been set in sharp contrast with mammalian tumours. This is not in accordance with the facts; they are not quite so simple. Peyton Rous remarked in one of his papers dealing with the filterability of his tumour that sometimes, and under the best conditions, cell-free filtrates are unaccountably innocuous. That, I am sure, has been the experience of all investigators who have worked for any length of time with the tumour. In my experience it has been unusual, for example, to obtain a potent filtrate from a tumour which has been induced by the inoculation of dried tumour tissue, or from a tumour which has been caused by the inoculation of filtrates damaged by heat. But when failure to obtain potent filtrates is an irregular thing the most obvious explanation is that the failure is caused by some technical difficulty. Filtration is not a simple regular process, and it is easy to understand irregular qualities of filtrates. But it has now been shown that technical difficulties cannot fully explain such failures. Dr. Andrews and myself have described how a Rous tumour lost its property of filterability, and how this property remained absent for more than five months and then suddenly reappeared. During this long period the tumour was transplantable only by means of living cells-that is, it behaved like the recognized tumours of mammals. Clearly, then, this property of filterability is not fixed; all ${ }^{-}$we can say is that generally a filtrate of the tumour is active-sometimes feebly, sometimes intensely; often it is quite inert. And since it has generally been accepted that a potent cell-free filtrate contains the tumour's cause, are we, then, to say that sometimes the cause is present in the filtriates and sometimes it is not? The solution of this apparently ridiculous dilemma will be shown later; at present $I$ merely wish to point out that sometimes the tumour's cause gives no sign of its presence.

The Effect of Heat on Filtrates.

It was shown by Rous and Murphy that tumour extracts are always robbed of their activity by exposure to a temperature of $55^{\circ} \mathrm{C}$. for fifteen minutes. This statement I can confirm completely. It has been tested very carefully, and the method employed is as follows: Not more than $3 \mathrm{c.cm}$. of the tumour extract is sealed up in a thinwalled, hard-glass test tube, which is then attached to the bulb of a standard thermometer and completely immersed in a water-bath kept at $55^{\circ} \mathrm{C}$. The thermometer and attached tube are shaken gently during the period of heating. Tested in this way, tumour extracts, whatever their initial potency, are invariably inactivated. Rous and Murphy regarded this result as evidence that the causative agent of the tumour had been destroyed; and of course it looks very like it. Whatever the agent is that is destroyed in such a short time at $55^{\circ} \mathrm{C}$. it is evidently very sensitive to heat, and judging by the thermal death points of other viruses, it is not likely to be a virus. This view is supported by a study of the effect of lower temperatures than $55^{\circ} \mathrm{C}$. upon a series of filtrates of tumours. A filtrate, usually through a Mandler candle, was made from all the routine tumours obtained during a period of more than six months-in all more than forty tumours. Each filtrate was tested at temperatures from $45^{\circ}$ to $55^{\circ} \mathrm{C}$., variations being made from time to time. During the period chosen the tumour was not very malignant, and as malignancy and activity of filtrates run parallel with one another, the filtrates were not very potent. In a few tests made, it was found that $0.5 \mathrm{c.cm}$. of Mandler filtrate was barely sufficient to induce a new tumour; 2 c.cm. was in each case adequate. All the samples of such filtrates were inactivated by exposure to $55^{\circ} \mathrm{C}$. for fifteen minutes; often $50^{\circ} \mathrm{C}$., and sometimes $45^{\circ} \mathrm{C}$., for fifteen minutes was sufficient. When suddenly the tumour became exceedingly malignant, metastasizing freely in liver, lungs, spleen, and elsewhere, and the filtrate became exceedingly active, inducing tumours in doses of $0.001 \mathrm{c.cm}$., then it was found that $54^{\circ} \mathrm{C}$. for fifteen minutes was insufficient to destroy all activity-the activity of the filtrate being merely reduced-but that exposure to $55^{\circ} \mathrm{C}$. for fifteen minutes was effective.

It is evident from this experience that the substance in the filtrate which is sensitive to heat is variable in amount or in quality in filtrates from different tumours.

Effects of Antiseptics upon Tumour Extracts.

One of the reasons given by Rous and Murphy for their belief that the filterable agent may be a virus was that antiseptics destroy the agent. It is only fair to state that Dr. Murphy has since changed his mind; he now thinks that it is unnecessary to assume a virus. His opinion of 1912 seems to me to be sounder than his opinion of 1926. Carbolic acid, corrosive sublimate, toluene, chloroform and 
other, hydrogen peroxide, formalin, acriflavine and hydrocyanic acid are some of the antiseptics which have been tested, and they are all effective, each in its own way, in abolishing the activity of tumour extracts. I shall describe briefly the effects of two only of these substances-namely, chloroform and acriflavine.

Chloroform acts very rapidly at incubator temperature. This is shown very clearly in Chart 1 , which represents the effect of $0.2 \mathrm{c.cm}$. of chloroform on $10 \mathrm{c.cm}$. of clear, cell-free, sand filtrate of a very malignant Rous sarcoma. The mixture of filtrate and chloroform was incubated in a large hard-glass tube in a water-bath at $37^{\circ} \mathrm{C}$. After incubation for one hour a sample was removed, the chloroform pumped off, and 1 c.cm. then inoculated intramuscularly into the right breast of Bird 411 ; after two and a quarter hours a second sample was inoculated in a dose of 1 c.cm. into the left breast of the same bird; and after three hours $1 \mathrm{c.cm}$. was inoculated into the right leg of tho bird. The control in this experiment was provided by incubating $10 \mathrm{c.cm}$. of the filtrate, contained in a hard-glass tube, for three hours in the same waterbath; of this incubated extract $0.2 \mathrm{c.cm}$. was inoculated into the left leg of Bird 411. It is shown by this experiment that in two and a quarter hours the activity of the filtrate has been enormously diminished by the chloroform; in three hours abolished. But since the fowl died in nineteen days it might be argued that there was not sufficient time allowed for the dose of filtrate treated with chloroform for the full three hours to manifest its activity. To provide against such a source of error a second fowl was inoculated with 2 c.cm. of such extract; in four months it has not developed a tumour.

Thus chloroform acts very rapidly. This, however, applies only to the ordinary impure chloroform used for common purposes in laboratories. When pure chloroform is used the action is much slower. I am indebted to Dr. Howard Mueller of Harvard for the intimation that this might be so.

Acriflavine acts slowly. The experiment represented by Chart 2 illustrates this very well. It will be seen from this that 1 in 5,000 acriflavine is unable in three hours to abolish the activity of an extract of a tumour. When such experiments are carried on for longer times-for example, six hours-it is found that the activity is further diminished but not entirely abolished. In order to inactivate a filtrate it is necessary to incubate the mixture overnight, and this often introduces a complication: simple incubation at $37^{\circ} \mathrm{C}$. for eighteen hours frequently robs a filtrate of its power to induce tumour formation. In order, therefore, to utilize the action of acriflavine in experiments of an analytical character it is necessary to devise other methods the details of which are omitted here for the sake of clarity.*

\section{Tuo Factors: Both Necessary for Cell Infection.}

We know that filtrates of the Rous tumour can be inactivated by heat and by antiseptics. By means of experiments such as that illustrated in Chart 3 it can be shown that the element destroyed by heat is not the same as that destroyed by acriflavine. The experiment shows that a tumour extract treated with acriflavine was quite inactive; an extract of the same tumour heated to $55^{\circ}$ to $56^{\circ} \mathrm{C}$. for eighteen minutes was also inactive. The two inactive fluids when mixed together acquired the power of inducing tumour formation.

The only criticism which can be passed upon experiments of this kind is that the chickens inoculated with acriflavine-treated extract happen to be naturally resistant, whereas the others are sensitive. This criticism, however, is not sound. The percentage of resistant birds cannot be determined absolutely, but it is, in any case, very small. Moreover, resistance is a graded quality. When the infective fluid is intensely active it is very rare to find a chicken resistant to its action. Only when the fluids which are inoculated are on the border-line of infectivity does one reveal differences in sensitiveness among any batch of chickens. The criticism, in any case, cannot

* The details and protocols ' of these researches will appear in a series of papers in the British Journal of Experimental Pathology. apply to the next series of experiments, which are illustrated in Charts 4 and 5 . In these experiments the same bird is used as control to the experiment. In the first experiment (Chart 4) the dose of acriflavine-treated tumour extract is the same in both breasts; the only difference between the two sides is that in the right breast the diluent is horse-serum broth medium, while in the left breast it is heat-inactivated extract of tumour. The quantities in such experiments as this are measured with the most scrupulous exactitude.

In the experiments represented by Chart 5 the controls, both of heat-inactivated and antiseptic-inactivated extracts, are included on the same bird. Similar experiments, with similar results, have been made with chloroform and with hydrocyanic acid as antiseptics.

From results such as these $I$ am satisfied that the production of a tumour with cell-free filtrates depends upon the conjoint action of two elements of the filtrate. One of these is rendered inactive by acriflavine or other antiseptic, and is therefore presumably a micro-organism; the other is readily inactivated by heat. As we have seen, it would appear probable that the agent which is destroyed by heat is variable in quantity (or in quality) in filtrates from different tumours.

Chart 6, which illustrates eight similar experiments, shows that innocuous filtrates (that is, filtrates from a "non-filterable" Rous tumour) have the same property of reactivating acriflavine-inactivated extracts as have extracts which have been heated to $55^{\circ} \mathrm{C}$. for fifteen minutes. It follows that inert filtrates are simply filtrates which contain none, or an insufficient amount, of this heatsensitive but absolutely essential factor. This factorwhich I have named the "specific factor," for reasons which will appear later-may bo present in variable amount, and it is only because of its activity that the presence of a virus can be shown in the Rous sarcoma. When it is absent the Rous sarcoma, like the average bird and mammalian tumours, cannot reveal its "cause." The peculiarity of the Rous tumour is that it manufactures in varying degree this accessory thermo-labile substance.

It is evident from these experiments that the agent which is destroyed by antiseptics (the virus) is unable, acting alone; to induce sarcoma formation. This fact appears to me to be very simple. It has its analogies in general bacteriology, where the phenomena are more widely known and appreciated. But the fact, when established in research connected with the subject of cancer, is apparently regarded as a diabolical mystification of a plain and straightforward problem. It is but right to state here that Professor Borrel, the pioneer of experimental cancer research, has for twenty years held the opinion on general grounds that the essential cause of tumours is a virus which requires prolonged preparatory irritation of the tissues before its latent powers can be manifested.

The use of the word "cause" in medicine is unfortunate and is always liable to misapprehension. What is generally understood by the word is, I assume, a factor which must be invariably present in the etiology of a disease. We cannot, if this be the meaning understood, regard the specific factor as the cause of the Rous sarcoma, because it is sometimes absent. The virus-that is, the element which may be destroyed by an antiseptic-is, so far as my experiments show, always present in the tumour whether the tumour be rery malignant or relatively benign. I regard the virus, therefore, as the cause of the sarcoma. Which of these two characters carries the specificity?

\section{Substitution Experiments.}

If an extract of the Rous fowl sarcoma be inactivated by heat and then there be added to it an extract of another tumour, the mixture does not induce sarcoma formation in the fowl or in the animal from which the second tumour was obtained-that is, a heat-inactivated extract of the Rous sarcoma cannot be restored to activity by the addi. tion of simple extract of a rat or mouse tumour. But when an extract of a Rous sarcoma is inactivated by means of an antiseptic or by centrifugation, the activity can be restored by the addition of extracts of some other tumours, 


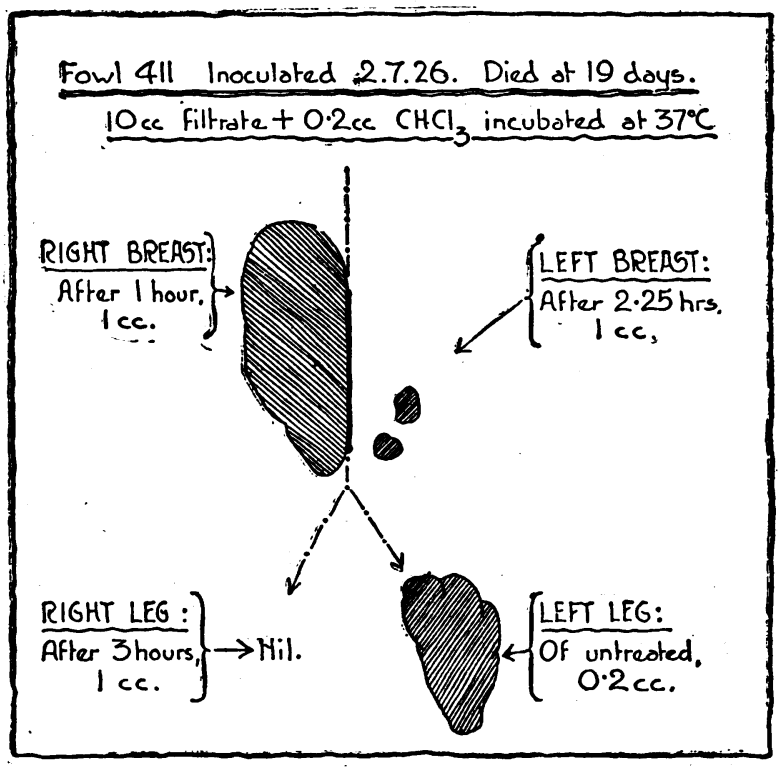

Chart 1.
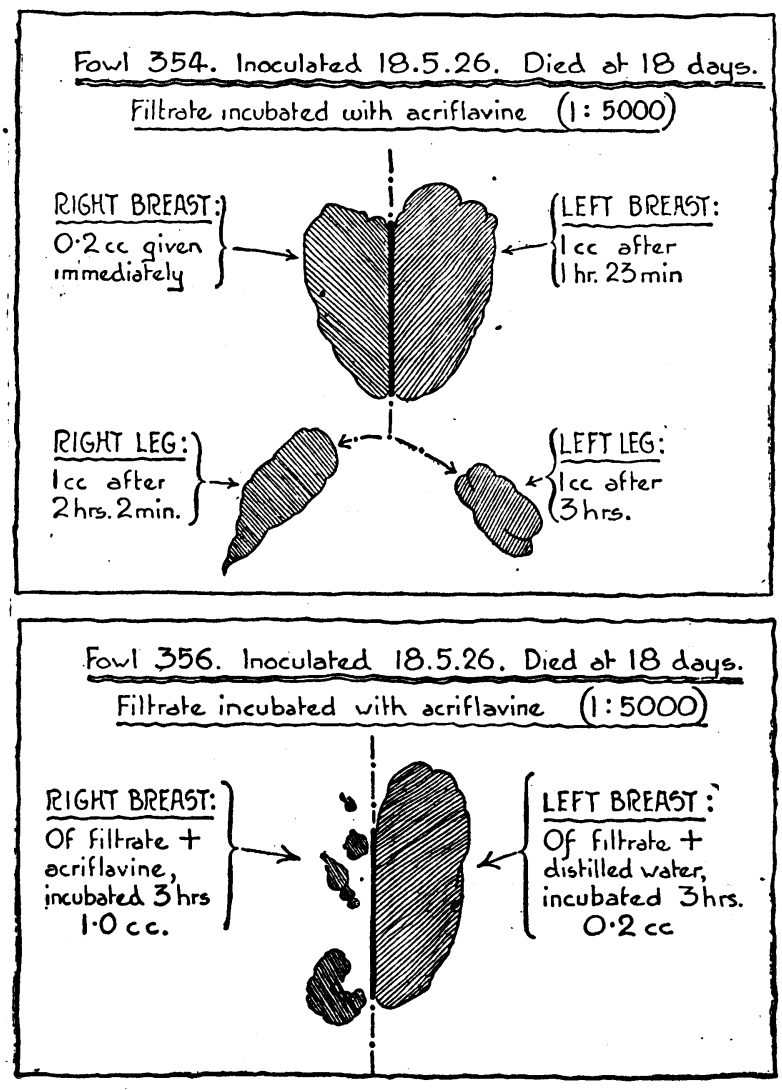

Chart 2

Chart 7 shows this very clearly. In this experiment the fowl sarcoma filtrate was treated with chloroform, the chloroform removed, and 1 c.cm. of the filtrate was then injected into the right breast of a fowl. Into the left breast of the same animal a mixture of $0.5 \mathrm{c.cm}$. of this chloroform-inactivated filtrate and $0.5 \mathrm{c.cm}$. of an extract of a tar tumour of the mouse was injected. A tumour grew in the left breast; the right breast remained quite negative. Chart 8 shows the same result for a human breast carcinoma.

Experiments such as these have been made with a large variety of tumours and with normal tissues. Among the tumours which have provided an agent which can replace

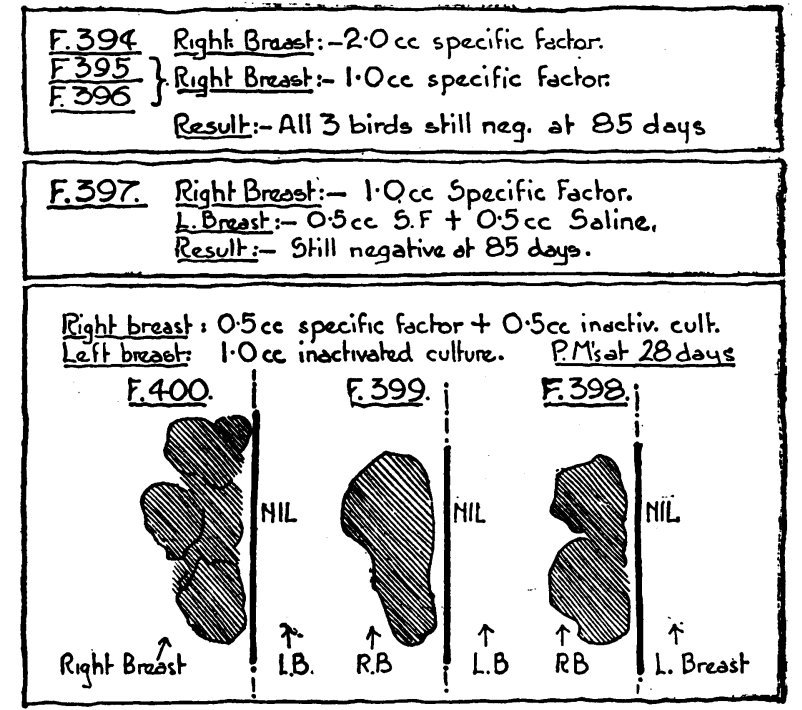

Chart 3.-All injections July 27th, 1926.

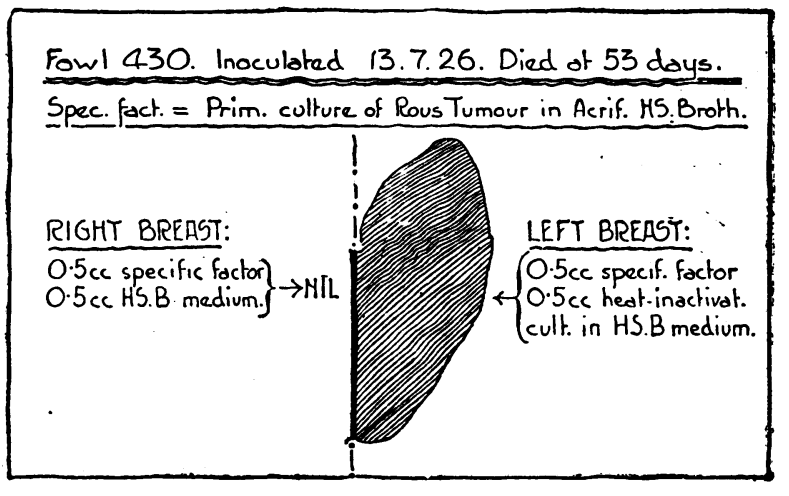

Chart 4.

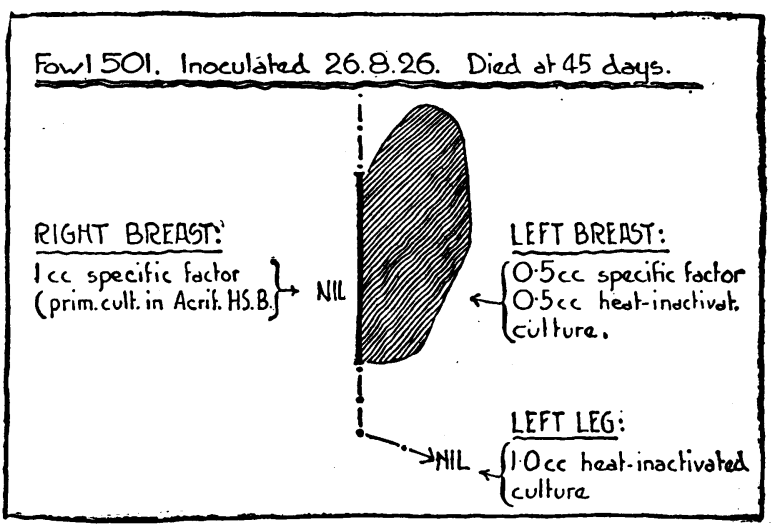

Chant 5.

that agent of the Rous sarcoma destroyed by antiseptics are carcinomata and sarcomata, both of man and animals. Normal tissues which have been tested are: embryonic tissues (chick, mouse, rat) more than 150 times; adult tissues of animals, including heart, lungs, muscle, brain, liver, and kidneys-and, in one instance, normal human uterus. Not once has it been possible with extracts of such normal tissues to replace the agent destroyed by antiseptic in the fowl sarcoma extract.

My interpretation of such experiments is as foliows: In the experiment represented by Chart 8 , for example, acriflavine has destroyed in the Rous tumour extract a microorganism; this interpretation is in accordance with the 
well known antiseptic action of acriflavine. The extract of mammary carcinoma has, as $I$ conceive it, provided a fresh supply of organisms which are able, in virtue of the presence of a sufficient amount of accessory factor of the fowl tumour, to infect the cells of the fowl inoculated.

These experiments show very clearly that the specificity of the Rous tumour extract is carried by the heat-labile

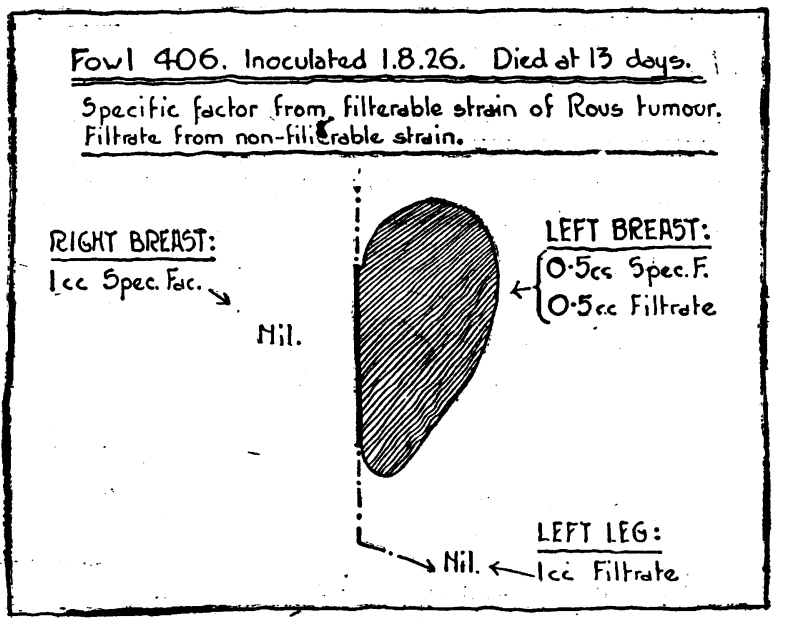

Chart 6.

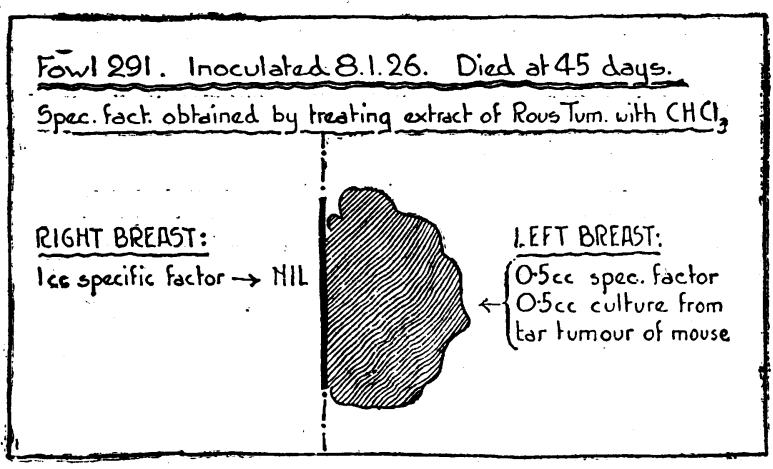

Chart 7.

agent, which has, for this reason, been called the "specific factor."

It has already been pointed out that extracts of normal tissues do not provide the agent which reactivates antiseptic-treated extracts of the Rous sarcoma. But certain tumours, one of which is a sarcoma of the mouse, have so far invariably failed also. This is one of the most puzzling facts yet met with, and I have no explanation which accounts for it satisfactorily.

The evidence that the agent which is extractable from many bird and mammalian tumours, and which has the power of restoring activity to inactive extracts of the Rous tumour, is a micro-organism is as follows: first the agent is killed by antiseptics, and secondly, it can be cultivated. 'The proof of cultivation' is obtained by the method described in a recent publicationnamely; by using as a medium serum broth to which is added a fragment of embryonic tissue. Chart 9 shows the method of experimentation adopted. Acriflavine-treated extract of Rous sarcoma is prepared; to measured portions of this are added in series: (1) a sample of serum-brothembryo culture medium, (2) a sample of a subculture in the same medium, and (3) samples of a subculture in different media. Quantities are measured precisely. The result of the experiment represented by Chart. 9 shows that the agent from a rat carcinoma survived in horse-serum-brothembryo and in horse-serum broth; but not in broth-embryo; it was not present in the. horse-serum-broth control tube, which had been incubated for the same period of time as the : cultures. Continuing with subcultures in this way, tumours have been obtained with remote (seventh) subcultures in media which contain embryo tissue. But there is a criticism which has been applied, and quite fairly, to these results: it is that possibly we are here dealing with a phenomenon similar to that discovered by Twort and now known as the "bacteriophage phenomenon." It is possible to argue that successive inoculations into tubes which contain living embryo induce repeatedly the production of the agent from the cells of the embryonic fragment. This' is not impossible, but it is very improbable. It must, of course, be settled before the last element of doubt has been removed.

Conclusions.

Does this new. knowledge bring us any nearer to the solution of the problem set forth at the beginning of this lecture? And further, is the answer compatible with the known facts of cancer structure and behaviour?

It seems to me, after considering the problem very thoroughly-and I hope with a sound knowledge of the accepted facts-that in the first place there is no incompatibility between new and old "fact"; and in the second place it shows that there is an agent contained in tumours of diverse origin and of diverse structure which has the supremely important property of reactivating an extract of the Rous sarcoma which has been inactivated by means of an antiseptic. The tumours in this respect are therefore linked together in a way which had never before been suspected; they are, indeed, a natural group. The agent which is common to these and which links them together
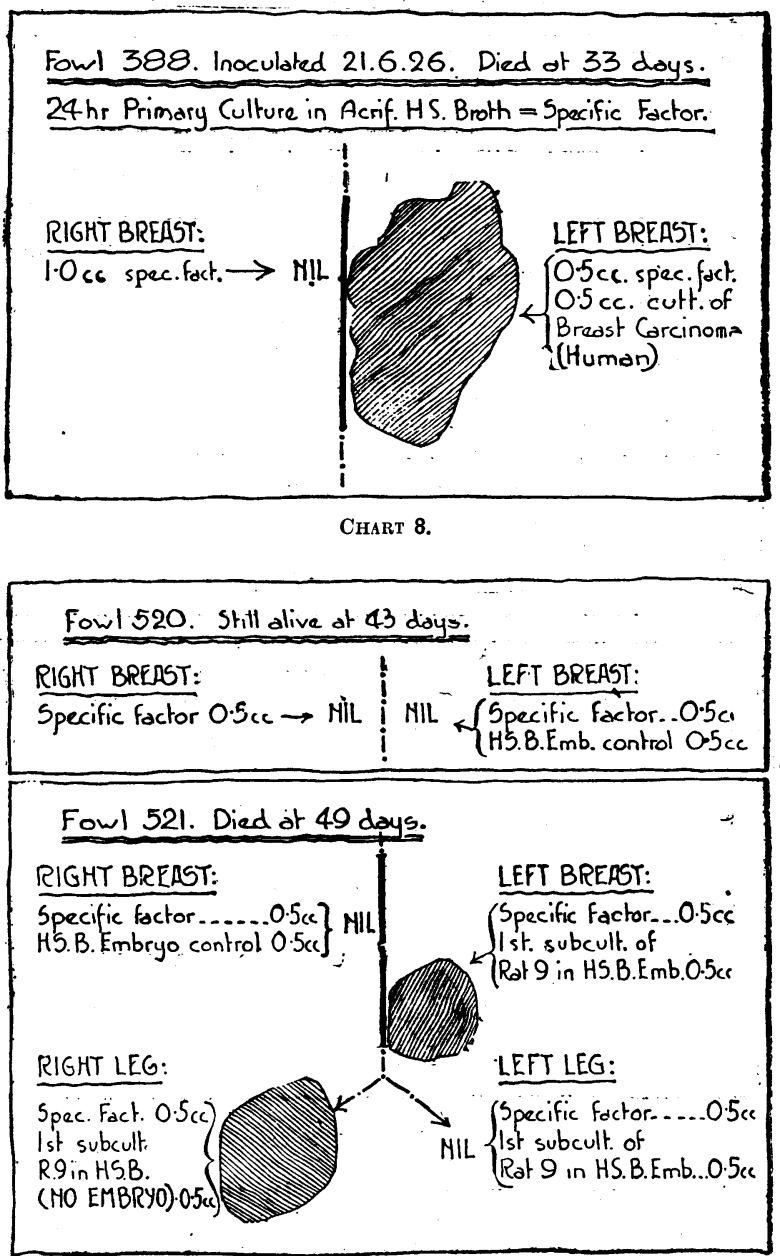

Chart 9.-All injections September 20th, 1926. Primary culture of Rous, in acriflavine. HS.B.= Specific factor.

in a group is killed by antiseptics and can be cultivated. Moreover, under special conditions it can be seen and photographed, as has been shown by my friend and colleague Mr. Barnard. I am satisfied that the simplest explanation of these observations is the correct onenamely, that the agent is a living, filterable microbe, and that it is the cause of new growths. 